\title{
Influence of pollen deprivation on the fore wing asymmetry of honeybee workers and drones
}

\author{
Hajnalka SzentgYÖRGYI, Krystyna CzeKoŃsKA, Adam ToFILSKI \\ Department of Pomology and Apiculture, University of Agriculture in Kraków, Al. 29. Listopada 54, 31-425, Kraków, \\ Poland
}

Received 22 May 2015 - Revised 14 September 2015 - Accepted 5 November 2015

\begin{abstract}
Environmental stress during development can be linked to changes in morphological traits of the organism such as increased fluctuating asymmetry. In suboptimal conditions, like food deprivation, developmental stability may be perturbed, because organisms are not able to buffer disturbances caused by stressors and, in effect, greater degrees of asymmetry can arise during development. In this study, honeybee workers and drones were reared in colonies with limited and unlimited access to pollen. The developmental instability of the workers and drones in these colonies was assessed using the asymmetry of their fore wing venation. Both workers and drones showed a similar directional asymmetry of size - in favour of the right wing - and significant, but dissimilar, differences of wing shape. Limited access to pollen caused some differences in the fluctuating asymmetry of size and shape in pollen-deprived workers and drones compared to the control bees. However, more pronounced differences were found due to replication than to pollen deprivation itself.
\end{abstract}

\section{directional asymmetry / fluctuating asymmetry / pollen deprivation / Apis mellifera / fore wing}

\section{INTRODUCTION}

Pollen is the main source of proteins, lipids, vitamins and minerals for both the developing brood and adult honeybees (Apis mellifera Linnaeus, 1758) (Brodschneider and Crailsheim 2010; Haydak 1970; Keller et al. 2005a, b). Young worker larvae are fed with royal jelly, however, in older workers and drone larvae it is largely replaced with raw floral pollen (Haydak 1970; Hrassnigg and Crailsheim 2005). The pollen is also consumed by adult drones in small amounts during the first few days after emergence (Free 1957; Haydak 1970; Szolderits and Crailsheim 1993; Schmickl and Crailsheim 2004), while adult

Electronic supplementary material The online version of this article (doi:10.1007/s13592-015-0415-5) contains supplementary material, which is available to authorized users.

Corresponding author: H. Szentgyörgyi, hajnalka.szentgyorgyi@ogr.ur.krakow.pl Manuscript editor: David Tarpy workers feed on pollen for a significantly longer period of time and consume much larger amounts of pollen (Szolderits and Crailsheim 1993; Hrassnigg and Crailsheim 2005).

In natural conditions, the availability of pollen changes seasonally because it depends on the diversity and abundance of flowering plants (Köppler et al. 2007; Odoux et al. 2012). During dearth periods or unfavourable weather conditions, honeybees depend on pollen stores (Fewell and Winston 1992); however, occasionally these stores can be insufficient and bees can suffer from malnutrition. The quantity of pollen available in the hive during brood rearing can directly affect the development of workers and drones (Hrassnigg and Crailsheim 2005; Kunert and Crailsheim 1988; Mattila and Otis 2006a). Workers suffering from pollen deprivation in most studies were found to live shorter (Janmaat and Winston 2000; Kunert and Crailsheim 1988; Mattila and Otis 2006b), start foraging earlier (Rueppell et al. 2006; Schmickl and Crailsheim 2002), have reduced hypopharyngeal glands 
(Crailsheim and Stolberg 1989) and ovaries (Pernal and Currie 2000), less effective in flight (Brodschneider et al. 2009) and have lower levels of vitellogenin and transferrin expression (Di Pasquale et al. 2013). Dwindling pollen stores during autumn is also a signal for bees to start rearing winter bees (Mattila and Otis 2007).

Among drones, limited access to pollen reduces their reproductive quality (Czekońska et al. 2015) and mating success (Couvillon et al. 2010). Pollen limitation can also affect bees' susceptibility to Nosema spp. (Wang and Moeller 1970; Huang 2012; Di Pasquale et al. 2013), Varroa destructor (Huang 2012; van Dooremalen et al. 2013) and other diseases (Brodschneider and Crailsheim 2010; de Grandi-Hoffman et al. 2010; Willard et al. 2011; Foley et al. 2012). In extreme cases, pollen deprivation can lead to the cannibalism of young larvae in order to feed older larvae (Schmickl and Crailsheim 2004) or cessation of brood rearing completely, to avoid producing highly impaired individuals (Imdorf et al. 1998; Kunert and Crailsheim 1988; Crailsheim and Hrassnigg 1998; Boes 2010).

Malnutrition, as described above, is a strong exogenous stressor affecting development and can be linked to changes in various morphological traits. One of these traits is the body symmetry of an organism. It is assumed that in suboptimal conditions developmental stability may be perturbed, because organisms are not able to buffer disturbances caused by exogenous environmental stressors and, as an effect, greater degrees of randomly appearing asymmetry arise during development. Such asymmetry caused by suboptimal developmental conditions is called fluctuating asymmetry and is independent of body side (van Valen 1962) and can affect various body parts (Palmer and Strobeck 2003; Palmer 1994). It should not be confused with directional asymmetry (van Valen 1962; Palmer 1994) which occurs when a certain trait is regularly more pronounced or bigger on one side of the body regardless of developmental instability (van Valen 1962; Palmer 1994). Fluctuating asymmetry has already been used as a measure of developmental stability in honeybees. It was found that drones are more asymmetrical than workers (Brückner 1976, but see Clarke 1997). Fluctuating asymmetry was also used in bee studies of rearing temperature (Jones et al. 2005), inbreeding (Brückner 1976; Clarke et al. 1986) and hybridization (Smith et al. 1997) or even toxicity (Ondo Zue Abaga et al. 2011). However, the results of these studies are inconsistent, and some failed to demonstrate detectable changes in the level of fluctuating asymmetry (Jones et al. 2005; Clarke et al. 1986; Smith et al. 1997) while others did (Brückner 1976; Ondo Zue Abaga et al. 2011). It was suggested that some of these differences between the various studies may result from the fact that the impact of stress on fluctuating asymmetry seems to be species-, trait- or stressor-specific (Beasley et al. 2013) or simply be a consequence of their under sampling (Babbitt et al. 2006).

The aim of our study was to describe the possible effect of pollen deprivation during brood rearing on the fore wing asymmetry of honeybee workers and drones. Asymmetry was assessed using measurements of fore wing venation. We also compared body mass to assess the extent of the effects of pollen deprivation method used.

\section{MATERIALS AND METHODS}

\subsection{Animals and experimental setup}

Honeybee (A. mellifera) workers and drones were reared in colonies with limited and unlimited access to pollen (called later: "pollen deprived" and "control", respectively). Bees were derived from Carniolan honeybees; however, the colonies' genotype was not controlled for in our study. All families were healthy with only low levels of mite infection reaching not more than 2-3 emerging individuals infected/100 bees/colony. The experiment was replicated four times for drones (May-June and JuneJuly in 2012 and May-June and June-July in 2013) and twice for workers (May-June and June-July in 2012). Each replication was done using six colonies. Three colonies out of six were assigned to the experimental group, and the remaining three were used as control. Each colony contained about 40,000 workers, and 20 wax combs in two boxes separated with queen excluder. There were 8 combs filled with brood in all stages of development, 10 combs partly filled with food, 1 experimental drone and 1 experimental worker comb. 
Pollen limitation was achieved using standard bottom pollen traps with 5.0-mm-diameter holes. Pollen traps were installed in all hives, but only in the three experimental colonies (with limited pollen access) the traps were activated 7 days prior and through the whole experiment, while in control groups (with unlimited pollen access) the traps were kept open continuously. Such limitations (pollen traps exclude about $60 \%$ of collected pollen as described by Keller et al. 2005b) allowed the rearing of both workers and drones, which otherwise - first of all drones, but in more extreme cases also workers - would be abandoned to avoid producing brood of lesser quality (Imdorf et al. 1998; Kunert and Crailsheim 1988; Crailsheim and Hrassnigg 1998; Boes 2010). During the experiment, bees had access to natural sources of pollen and their pollen stores in combs.

On the first day of each replication, the queens in all colonies were isolated on separate worker combs to lay eggs. After $24 \mathrm{~h}$, queens were moved to drone combs and kept isolated there for another $24 \mathrm{~h}$ to lay eggs. Next, the queens were released from the cages while the combs with eggs were isolated to prevent queens from laying eggs on them again. One day prior to the expected emergence of workers and drones, the combs were moved to incubators with a constant temperature of $34^{\circ} \mathrm{C}$. During the next few days the incubators were inspected every $2 \mathrm{~h}$. The first 30 workers and 30 drones emerging from each colony were weighed using a METTLER TOLEDO XP analytical balance with a readability of $0.001 \mathrm{mg}$. In total, 165 workers (90 from the pollen-deprived group and 75 from the control group) and 507 drones (255 from the pollendeprived group and 252 from the control group) were weighed. The rest of the bees emerging during the next $24 \mathrm{~h}$ were moved to cages and kept in incubators until their fifth day of life.

\subsection{Wing measurements}

Fore wings of 5-day-old individuals were measured. Wings were mounted in photographic frames and scanned using Nikon Super CoolScan 5000 ED scanner (resolution 2400 dpi). Nineteen landmarks (Figure 1) were marked on the fore wings using DrawWing software (Tofilski 2004). Each wing was automatically measured three times using
DrawWing. The three measurements are independent of each other and were used to assess measurement error (Palmer 1994; Graham et al. 2010). The configurations of landmarks were aligned using Procrustes superimposition (Dryden and Mardia 1998) in MorphoJ software (Klingenberg 2011). The landmarks were analysed using methods of geometric morphometrics. The methods allow to separate size and shape. As a measure of size, centroid size (Dryden and Mardia 1998) was used. Shape, on the other hand, was described by Procrustes coordinates, which were scaled to the same size. We have analysed asymmetry of both size and shape. Size asymmetry was measured as the absolute difference between the centroid sizes of the right and the left fore wing divided by the mean centroid size and multiplied by 100 (percentage of centroid size difference between left and right wing). Shape asymmetry was measured as the Procrustes distance between the shapes of the right and the left wing, and it is further called Procrustes FA score. Centroid sizes and Procrustes FA scores were calculated in MorphoJ software (Klingenberg 2011).

Individuals with destroyed or dirty wings were excluded from further analysis. In total, 1507 workers (765 from the pollen-deprived group and 742 from the control group) and 1100 drones (689 from the pollen-deprived group and 411 from the control group) were used.

Coordinates of the landmarks were used to calculate 25 distances, which are called vein lengths (Figure 1). As a measure of wing vein asymmetry, index FA2 $=|R-L| /((R+L) / 2)$ was used (Palmer 1994) where $R$ and $L$ are lengths of the right and the left vein, respectively.

\subsection{Statistical analysis}

The significance of directional and fluctuating asymmetry was tested using two-way mixed-model ANOVA (Procrustes ANOVA) in MorphoJ software (Klingenberg 2011). The measurement error was relatively small. Statistica software v.10 (StatSoft Inc. 2011) was used for further statistical analysis. Differences in body mass between replications and experimental groups were analysed using ANOVA. Size differences between replications and treatments were compared using twoway ANOVA. On the other hand, both centroid size 

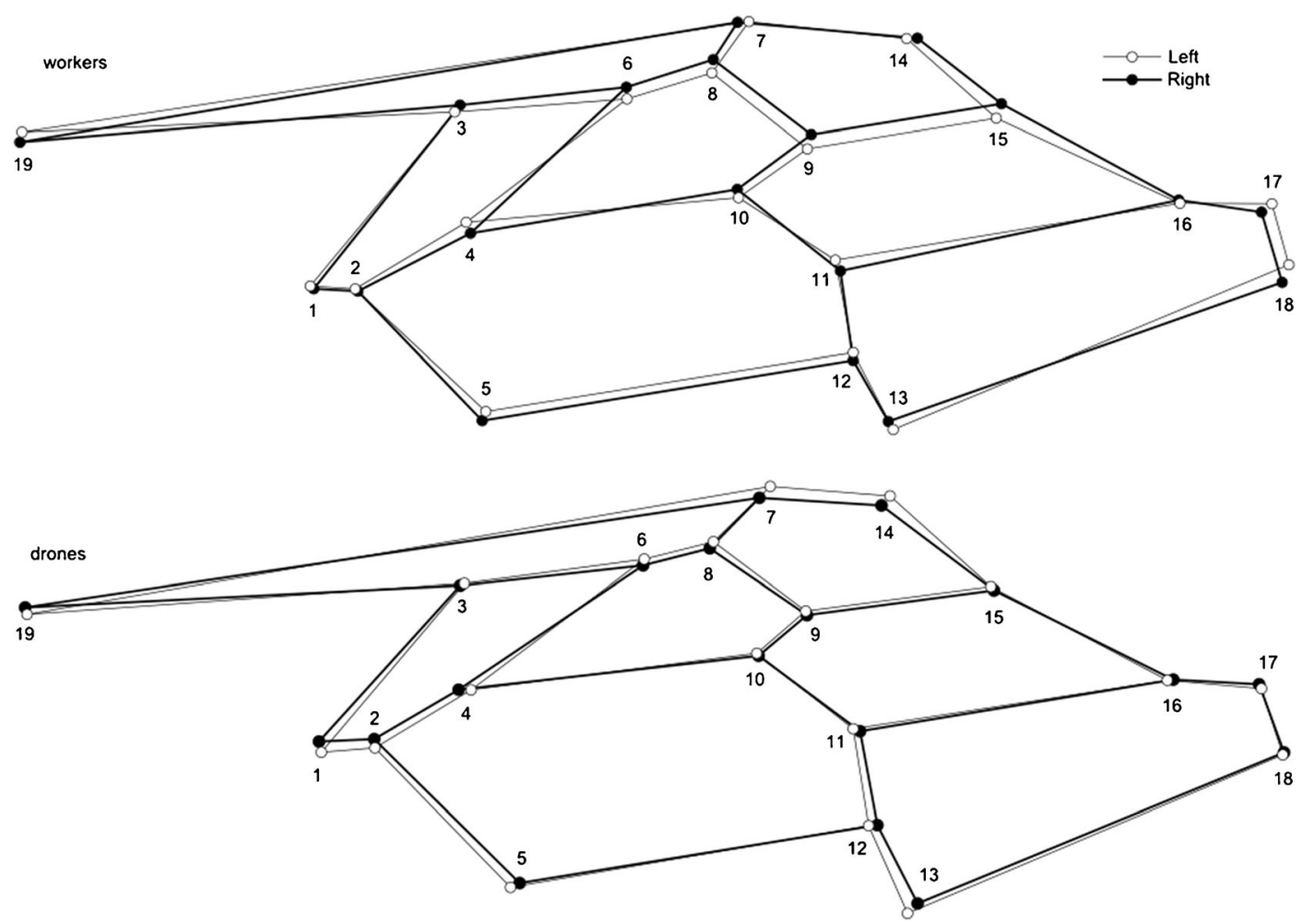

Figure 1. Scheme of 19 honeybee wing landmark points for morphometric measurements and wing venation for drone and worker honeybees. The wing veins are determined as the distance between the two landmark points measured in a straight line. The black lines indicate the right wing, and the grey lines indicate the left wing. Differences between the sides were magnified ten times to make them more visible

asymmetry and Procrustes FA scores were analysed using Kruskal-Wallis test for non-parametric comparison, due to not normal distribution.

Vein lengths were also compared to assess the directional and fluctuating wing asymmetry. To estimate directional asymmetry, one-way ANOVA was used to compare vein lengths between the left and the right wing. Fluctuating asymmetry was assessed by comparing FA2 indexes between experimental groups using one-way ANOVA. In all cases when comparing wing vein lengths, the significant $p$ value was set at 0.002 (Bonferroni's correction for 25 comparisons).

\section{RESULTS}

Significant directional asymmetry of fore wing size (Supplementary Table S1) was found in both workers $(F(1,1504)=392.22, P<0.001)$ and drones $(F(1,1094)=164.35, P<0.001)$. The right wings were larger (in terms of centroid size) than the left wings in both workers and drones. Mean \pm SD centroid size of right and left wings were $649.83 \pm 12.54$ and $647.90 \pm 12.31$, respectively, in workers and $892.08 \pm 22.80$ and $889.75 \pm 23.28$, respectively, in drones. The shape of left and right fore wings also differed significantly in both workers $(F(34,51,136)=51.78, P<0.001)$ and drones $(F(34,37,196)=20.71, P<0.001)$ (Supplementary Table S2). The pattern of differences in wing shape between the right and the left wings was different in workers and drones (Figure 1).

The presence of directional asymmetry was also confirmed by the analysis of wing vein lengths (Supplementary Table S3 and S4). In workers, 10 out of 25 vein lengths differed significantly between the right and the left wing (Supplementary Table S3). Eight of those veins were longer in the right wing and 2 veins were 
longer in the left wing. In drones, only 1 of the 25 veins was significantly longer in the right in comparison to the left wing (Supplementary Table S4).

In colonies with limited access to pollen, the mass of pollen collected in the pollen traps (and excluded from feeding the larvae) was between 330 and $2031 \mathrm{~g}$, with a mean $( \pm \mathrm{SD})$ value of 1444 $\pm 661 \mathrm{~g}$ per colony. The mean body mass of both workers and drones developing in pollen deprived colonies was smaller than in control colonies (workers $106.3 \pm 10.0 \mathrm{mg}$ and $110.0 \pm 14.0 \mathrm{mg}$; drones $253.3 \pm 20.5 \mathrm{mg}$ and $262.2 \pm 19.1 \mathrm{mg}$, pollen deprived and control, respectively). However, the differences were significant only in drones $(F(1,507)=21.9, P<0.001)$ but not in workers $(F(1,165)=2.28, P=0.133)$. Replications differed significantly both in workers $(F(1$, $165)=13.81, P<0.001)$ and in drones $(F(1$, $507)=11.17, P<0.001)$, but no interactions were found between replications and pollen access (workers $F(1,165)=0.52, P=0.472$; drones $F(1,507)=0.78, P=0.506)$.

Fore wing size of pollen-deprived drones was significantly different from that of control drones, but pollen-deprived and control workers did not differ in fore wing size (Supplementary Table S1). In drones, the size also differed between replications (Supplementary Table S1), showing additionally a significant interaction between treatment and replication $(F(3,1092)=55.21$, $P<0.001$ ) (Figure 2). In the case of workers, treatment groups showed a significant interaction with replications $(F(1,1503)=67.96, P<0.001)$; however, replications did not differ significantly (Supplementary Table S1, Figure 2).

Asymmetry of fore wing size did not differ significantly between pollen-deprived and control group regardless of sexes (Table I). Significant differences were present only between replications in drones, but not in workers (Figure 2). Wing size asymmetry (expressed as $\%$ of mean centroid size \pm SD) in drones $(0.554 \% \pm 0.467)$ was higher than in workers $(0.516 \% \pm 0.400)$, but the difference was not statistically significant $(H(1,2607)=1.82, P=0.177)$.

Wing shape differed significantly between pollen-deprived and control group and also between replications both in workers and drones (Supplementary Table S2). Pollen-deprived workers had higher asymmetry of wing shape (measured as Procrustes FA score) than control ones (Table II), but in drones this relationship was not significant (Table II). Wing shape asymmetry was significantly different between replications both in workers and drones (Figure 2). Drones also had a higher shape asymmetry than workers (workers $0.0167 \pm 0.00513$; drones 0.0177 $\pm 0.00680, H(1,2606)=7.12, P<0.008)$.

There were no significant differences between control and pollen-deprived group in vein length asymmetry (measured as FA2 index) neither in workers (Supplementary Table S4) nor in drones (Supplementary Table S4).

\section{DISCUSSION}

The results presented here showed clearly that there is a significant directional asymmetry of honeybee fore wings. The right wings were larger than the left wings, consistent across experimental treatment and replication. The presence of directional asymmetry of honeybee wings was reported in some studies (Smith et al. 1997; Schneider et al. 2003), but in most of them it was not significant (Clarke and Oldroyd 1996; Clarke 1997; Clarke 1998; Jones et al. 2005; Ondo Zue Abaga et al. 2011). However, all these studies used a much lower number of bees (ranging from tens to a hundred), and therefore had a much lower sample size. Our study allowed us the detection of less pronounced differences. In other species, such directional asymmetries were also observed (Pélabon and Hansen 2008).

It was earlier suggested that directional asymmetry is genetically determined and adaptive (Van Valen 1962; Windig and Nylin 1999), therefore, it should not be used as a measure of developmental stability (Palmer and Strobeck 1992). Moreover, its presence can make the interpretation of fluctuating asymmetry more difficult. It was even advised that characters that show directional asymmetry should not be used for analysis of fluctuating asymmetry (Palmer and Strobeck 2003). In the present study, both size and shape of wing venation showed directional asymmetry. When analysed individually, also many of the wing veins showed significant directional 

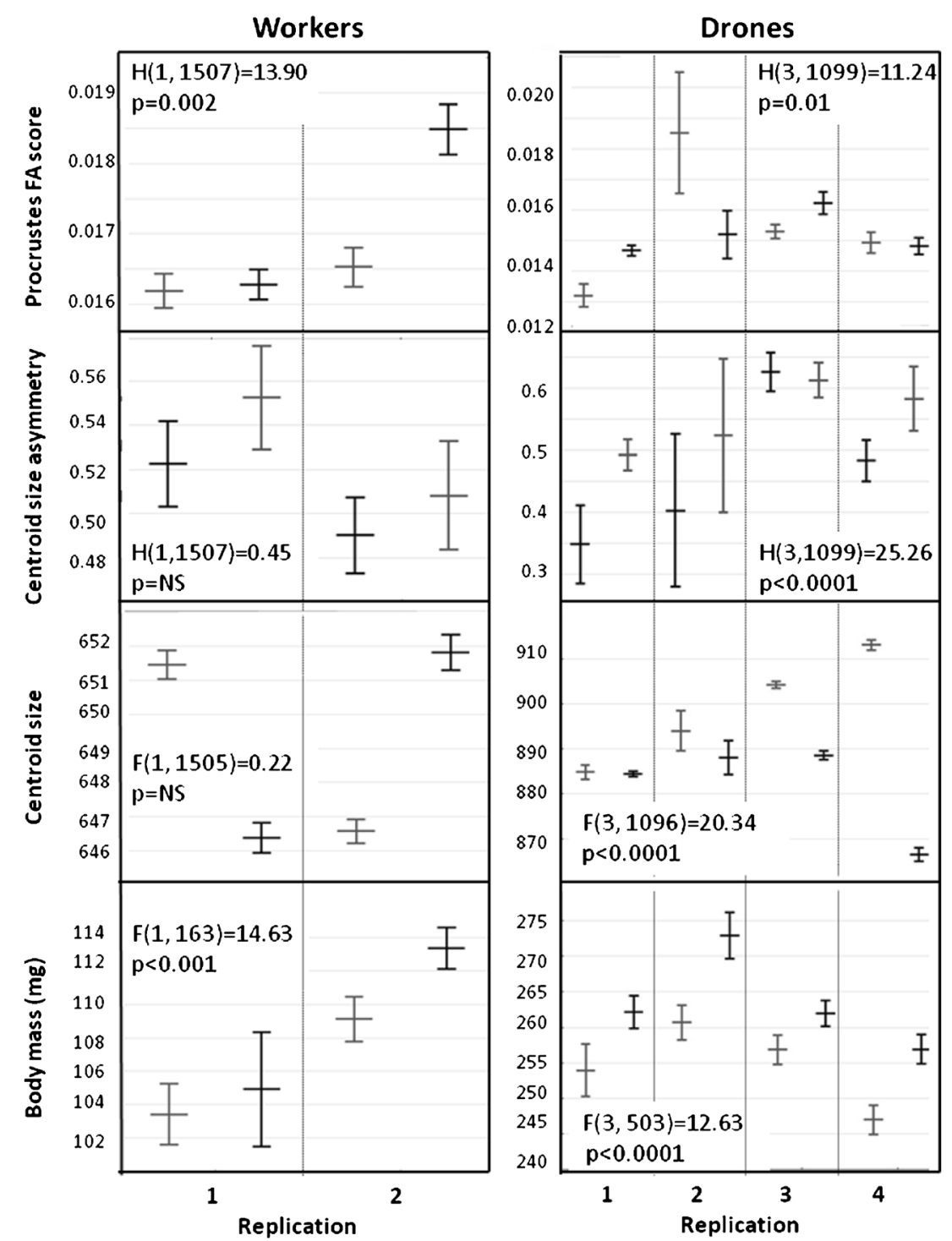

Figure 2. Mean \pm SE of body mass (mg), wing's centroid size, centroid size asymmetry (measured as \% of mean centroid size) and Procrustes FA score calculated by using 19 wing landmark points of honeybee workers and drones that were reared in pollen-deprived and control colonies. For calculating differences between replications, the results of the Kruskal-Wallis test (Procrustes FA scores, centroid size asymmetry) or one-way ANOVA (centroid size, body mass) were used. Grey lines indicate control bees, and black lines indicate pollen-deprived bees

asymmetry. Therefore, the data presented here about fluctuating asymmetry should be interpreted with care.

The wing shape differed significantly between pollen-deprived and control groups; however, only in one replication did pollen-deprived workers showed higher fluctuating asymmetry of wing shape. There were, however, significant differences in fluctuating asymmetry between replications. This suggests that fluctuating asymmetry was mainly affected by factors other than the limited access to pollen.

On the other hand, pollen limitation did affect the body mass of bees, indicating that, in comparison to wing asymmetry, body mass is a better indicator of pollen availability 
Table I. Fore wing size asymmetry (measured as \% of mean centroid size) of workers and drones that were reared in pollen-deprived and control colonies

\begin{tabular}{lllll}
\hline Sex & Pollen deprived & Control & Kruskal-Wallis test & $P$ \\
\hline Workers & $0.50 \pm 0.39$ & $0.54 \pm 0.40$ & $H(1,1507)=3.60$ & NS \\
Drones & $0.55 \pm 0.47$ & $0.56 \pm 0.46$ & $H(1,1099)=0.19$ & NS \\
\hline
\end{tabular}

$N S$ not significant

during development. The pollen traps, though they significantly reduced the amount of pollen transported to the nest, did not exclude it completely (Keller et al. 2005b). It is possible that such pollen deprivation was not enough to affect significantly wing asymmetry, although it did affect significantly body mass. Our results are in agreement with earlier findings showing that pollen-deprived bees are of smaller mass (Brodschneider and Crailsheim 2010). Generally, lower body mass is suggested to be the consequence of fewer nutrients (mostly protein) - due to shortages in pollen availability in the hive-received from nursing bees feeding the larvae during the first phase of their development. However, the study of Mattila and Otis (2006c) has showed that the response of honeybees to pollen availability during larval development is highly variable and dependant also on other environmental factors. In our study, nursing bees were able to rear the brood in spite of the active pollen traps installed in the hive. Yet, the amount of food and nutrition was insufficient to rear individuals of the same size as control ones-especially drones - which agrees with the results described earlier in literature (Levin and Haydak 1951; De Groot 1953; Kunert and Crailsheim 1988). It was also shown that drones reared in hopelessly queenless colonies, which can be malnourished, have lower mass and wing length in comparison to drones reared in queenright colonies (Gençer and Firatli 2005).

The colony can protect its larvae during development from temporary pollen shortages, simply by storing more food in the hive (Fewell and Winston 1992). Therefore, the less pronounced difference between treatments compared to replications is not surprising. Young larvae are not fed with collected fresh pollen directly, but mostly through royal jelly produced by the nursing bees. The total amount of directly fed pollen is negligible, reaching around $5 \%$ of the total protein requirement for both workers and drones (Hrassnigg and Crailsheim 2005). Using pollen traps to deprive developing bees of their protein source might have a lower effect than expected, because of available pollen stores in the comb which may allow other factors to affect development. If the colonies were in good condition and had enough pollen already stored in the hive, nurse bees could feed the larvae with brood food utilizing stored bee bread. Large pollen stores could result in less pronounced differences in body symmetry between experimental groups. Experimental conditions, due to replications conducted at different times during the season, could

Table II. Fore wing shape asymmetry (measured as Procrustes FA score) of workers and drones that were reared in pollen-deprived and control colonies

\begin{tabular}{lllll}
\hline \multicolumn{1}{c}{ Sex } & Pollen deprived & Control & Kruskal-Wallis test & $P$ \\
\hline Workers & $0.0171 \pm 0.0081$ & $0.0163 \pm 0.0050$ & $H(1,1507)=8.99$ & 0.003 \\
Drones & $0.0177 \pm 0.0071$ & $0.0175 \pm 0.0062$ & $H(1,1099)=0.005$ & NS \\
\hline
\end{tabular}

NS not significant 
affect the development more than pollen deprivation, because pollen sources change during the course of the season (Köppler et al. 2007; Odoux et al. 2012; Di Pasquale et al. 2013). This is also in agreement with the results of Mattila and Otis (2006c) showing how worker traits are differently modified by pollen availability in various years and at different times of the year.

We conclude that fore wing asymmetry in workers and drones is not a good indicator of pollen deprivation during development. First of all, both workers and drones have a strong directional fore wing asymmetry which makes analysis of fluctuating asymmetry difficult. Moreover, in comparison to other factors, the influence of pollen deprivation on wing asymmetry was relatively small. Body mass seems to be a better indicator of pollen deprivation.

\section{ACKNOWLEDGMENTS}

We thank Bernadeta Rzeźnicka for technical assistance. This study was supported by the Polish National Science Centre (NCN) grant number UMO-2013/10/E/ NZ9/00682 and MSHE grant number DS-3500.

\section{OPEN ACCESS}

This article is distributed under the terms of the Creative Commons Attribution 4.0 International License (http://creativecommons.org/licenses/by/4.0/), which permits unrestricted use, distribution, and reproduction in any medium, provided you give appropriate credit to the original author(s) and the source, provide a link to the Creative Commons license, and indicate if changes were made.

Influence d'une privation de pollen sur l'assymétrie de l'aile antérieure des ouvrières et des mâles d'abeilles

assymétrie directionnelle / assymétrie fluctuante / disponibilité en pollen / Apis mellifera / morphologie aile / effet sur développement

Der Einfluss von Pollenmangel auf die Asymmetrie der Flügel bei Arbeiterinnen und Drohnen der Honigbiene

Direktionale Assymetrie / Pollenmangel / Apis mellifera / Vorderflügel

\section{REFERENCES}

Babbitt, G.A., Kiltie, R., Bolker, B. (2006) Are fluctuating asymmetry studies adequately sampled? Implications of a new model for size distribution. Am. Nat. 167, 230-245

Beasley, D.A.E., Bonisoli-Alquati, A., Mousseau, T.A. (2013) The use of fluctuating asymmetry as a measure of environmentally induced developmental instability: a meta-analysis. Ecol. Indicat. 30, 218-226

Boes, K.E. (2010) Honeybee colony drone production and maintenance in accordance with environmental factors: an interplay of queen and worker decisions. Insectes Soc. 57, 1-9

Brodschneider, R., Crailsheim, K. (2010) Nutrition and health in honey bees. Apidologie. 41 (3), 278-294

Brodschneider, R., Riessberger-Gallé, U., Crailsheim, K. (2009) Flight performance of artificially reared honeybees (Apis mellifera). Apidologie. 40 (4), 441-449

Brückner, D. (1976) The influence of genetic variability on wing symmetry in honeybees (Apis mellifera). Evolution. $30(1), 100-108$

Clarke, G.M. (1997) The genetic basis of developmental stability. III. Haplodiploidy: Are males more unstable than females? Heredity. 51, 2021-2028

Clarke, G.M. (1998) The genetic basis of developmental stability. V. Inter and intra- individual character variation. Heredity. 80, 562-567

Clarke, G.M., Oldroyd, B.P. (1996) The genetic basis of developmental stability in Apis mellifera. II. Relationships between character size, asymmetry and single-locus heterozygosity. Genetica. 97, 211-224

Clarke, G.M., Brand, G.W., Whitten, M.J. (1986) Fluctuating asymmetry: A technique for measuring developmental stress caused by inbreeding. Aust. J. Biol. Sci. 39, 145-153

Couvillon, M.J., Hughes, W.O.H., Perez-Sato, J.A., Martin, S.J., Roy, G.G.F., Ratnieks, F.L.W. (2010) Sexual selection in honey bees: colony variation and the importance of size in male mating success. Behav. Ecol. 21 (3), 520-525

Crailsheim, K., Hrassnigg, N. (1998) Adaptation of hypopharyngeal gland development to the brood status of honeybee (Apis mellifera L.) colonies. J. Insect Physiol. 44 (10), 929-939

Crailsheim, K., Stolberg, E. (1989) Influence of diet, age and colony condition upon intestinal proteolytic activity and size of the hypopharyngeal glands in the honeybee (Apis mellifera L.). J. Insect Physiol. 35(8), 595-602

Czekońska, K., Chuda-Mickiewicz, B., Samborski, J. (2015) Quality of honeybee drones reared in colonies with limited and unlimited access to pollen. Apidologie. 46(1), 1-9

de Grandi-Hoffman, G., Chen, Y., Huang, E., Huang, M.H. (2010) The effect of diet on protein concentration, hypopharyngeal gland development and virus load in 
worker honey bees (Apis mellifera L.). J. Insect Physiol. 56 (9), 1184-1191

de Groot, A.P. (1953) Protein and amino acid requirements of the honey bee (Apis mellifera L.). Physiol. Comp. Oecologia. 3, 197-285

Di Pasquale, G., Salignon, M., Le Conte, Y., Belzunces, L.P., Decourtye, A., Kretzschmar, A., Suchail, S., Brunet, J.-L., Alaux, C. (2013) Influence of pollen nutrition on honey bee health: do pollen quality and diversity matter? PLoS One. 8(8), e72016

Dryden, I.L., Mardia, K.V. (1998) Statistical Shape Analysis. John Wiley \& Sons, Chichester

Fewell, J.H., Winston, M.L. (1992) Colony state and regulation of pollen foraging in the honey bee, Apis mellifera L. Behav. Ecol. Sociobiol. 30 (6), 387-393

Foley, K., Fazio, G., Jensen, A., Hughes, W.O.H. (2012) Nutritional limitation and resistance to opportunistic Aspergillus parasites in honey bee larvae. J. Invertebr. Pathol. 111 (1), 68-73

Free, J.B. (1957) The food of adult drone honeybees (Apis mellifera ). Brit J Anim Behav. 5(1), 7-11

Gençer, H.V., Firatli, C. (2005) Reproductive and morphological comparisons of drones reared in queenright and laying worker colonies. J. Apic. Res. 44 (4), 163-167

Graham, J.H., Raz, S., Hel-Or, H., Nevo, E. (2010) Fluctuating asymmetry: methods, theory, and applications. Symmetry. 2 (2), 466-540

Haydak, M.H. (1970) Honey bee nutrition. Annu. Rev. Entom. 15, 143-156

Hrassnigg, N., Crailsheim, K. (2005) Differences in drone and worker physiology in honeybees (Apis mellifera). Apidologie. 36 (2), 255-277

Huang, Z.Y. (2012) Pollen nutrition affects honey bee stress resistance. Terr. Arthropod Rev. 5, 175-189

Imdorf, A., Rickli, M., Kilchenmann, V., Bogdanov, S., Wille, H. (1998) Nitrogen and mineral constituents of honey bee worker brood during pollen shortage. Apidologie. 29(4), 315-325

Janmaat, A.F., Winston, M.L. (2000) The influence of pollen storage area and Varroa jacobsoni Oudemans parasitism on temporal caste structure in honey bees (Apis mellifera L.). Insectes Soc. 47 (2), 177-182

Jones, J., Helliwell, P., Beekman, M., Maleszka, R., Oldroyd, B.P. (2005) The effects of rearing temperature on developmental stability and learning and memory in the honey bee, Apis mellifera . J. Comp. Physiol. A. $191(12), 1121-1129$

Keller, I., Fluri, P., Imdorf, A. (2005a) Pollen nutrition and colony development in honey bees: part I. Bee World. 86(1), 3-10

Keller, I., Fluri, P., Imdorf, A. (2005b) Pollen nutrition and colony development in honey bees: part I. Bee World. 86(2), 27-34

Klingenberg, C.P. (2011) MorphoJ: An integrated software package for geometric morphometrics. Mol Ecol Resources. 11 (2), 353-357
Köppler, K., Vorwohl, G., Koeniger, N. (2007) Comparison of pollen spectra collected by four different subspecies of the honey bee Apis mellifera . Apidologie. 38 (4), 341-353

Kunert, K., Crailsheim, K. (1988) Seasonal changes in carbohydrate, lipid and protein content in emerging worker honeybees and their mortality. J Apic Res. 27, 13-21

Levin, M.D., Haydak, M.H. (1951) Seasonal variation in weight and ovarian development in the worker honeybee. J. Econ. Entomol. 44, 54-57

Mattila, H.R., Otis, G.W. (2006a) Influence of pollen diet in spring on development of honey bee (Hymenoptera: Apidae) colonies. J. Econ. Entomol. 99, 604-613

Mattila, H.R., Otis, G.W. (2006b) Effects of pollen availability and Nosema infection during the spring on division of labor and survival of worker honey bees (Hymenoptera: Apidae). Environ. Entomol. 35, 708-717

Mattila, H.R., Otis, G.W. (2006c) The effects of pollen availability during larval development on the behaviour and physiology of spring-reared honey bee workers. Apidologie. 37 (5), 533-546

Mattila, H.R., Otis, G.W. (2007) Dwindling pollen resources trigger the transition to broodless populations of long-lived honeybees each autumn. Ecol. Entomol. 32, 496-505

Odoux, J.-F., Feuillet, D., Aupinel, P., Loublier, Y., Tasei, J.-N., Mateescu, C. (2012) Territorial biodiversity and consequences on physico-chemical characteristics of pollen collected by honey bee colonies. Apidologie. 43 (5), 561-575

Ondo Zue Abaga, N., Alibert, P., Dousset, S., Savadogo, P.W., Savadogo, M., Sedogo, M. (2011) Insecticide residues in cotton soils of Burkina Faso and effects of insecticides on fluctuating asymmetry in honey bees (Apis mellifera Linnaeus). Chemosphere. 83 (4), 585-592

Palmer, A.R. (1994) Fluctuating asymmetry analyses: A primer. In: Markow, T.A. (ed.) Developmental Instability: Its Origins and Evolutionary Implications, Contemporary Issues in Genetics and Evolution, pp. 335364. Springer, Netherlands

Palmer, A.R., Strobeck, C. (1992) Fluctuating asymmetry as a measure of developmental stability: Implications of non-normal distributions and power of statistical tests. Acta Zool Fenn. 191, 55-70

Palmer, A.R., Strobeck, C. (2003) Fluctuating asymmetry analyses revisited. In: Polak, M. (ed.) Developmental Instability (DI): Causes and Consequences, pp. 279319. Oxford University Press, Oxford

Pélabon, C., Hansen, T.F. (2008) On the adaptive accuracy of directional asymmetry in insect wing size. Evolution. 62 (11), 2855-2867

Pernal, S.F., Currie, R.W. (2000) Pollen quality of fresh and 1 -year-old single pollen diets for worker honey bees (Apis mellifera L.). Apidologie. 31 (3), 387-409

Rueppell, O., Page Jr., R.E., Fondrk, M.K. (2006) Male behavioural maturation rate responds to selection on pollen hoarding in honeybees. Anim. Behav. 71(1), 227-234 
Schmickl, T., Crailsheim, K. (2002) How honeybees (Apis mellifera L.) change their broodcare behaviour in response to non-foraging conditions and poor pollen conditions. Behav. Ecol. Sociobiol. 51 (5), 415-425

Schmickl, T., Crailsheim, K. (2004) Inner nest homeostasis in a changing environment with special emphasis on honey bee brood nursing and pollen supply. Apidologie. 35 (3), 249-263

Schneider, S.S., Leamy, J., Lewis, A., Degrandi-Hoffman, G. (2003) The influence of hybridization between African and European honeybees, Apis mellifera, on asymmetries in wing size and shape. Evolution. 57 (10), 2350-2364

Smith, D.R., Crespi, B.J., Bookstein, F.L. (1997) Fluctuating asymmetry in the honey bee, Apis mellifera: effects of ploidy and hybridization. J. Evol. Biol. 10(4), 551-574

StatSoft, Inc. (2011) STATISTICA (data analysis software system), version 10. www.statsoft.com

Szolderits, M.J., Crailsheim, K. (1993) A comparison of pollen consumption and digestion in honeybee (Apis mellifera carnica) drones and workers. J. Insect Physiol. 39 (10), 877-881
Tofilski, A. (2004) DrawWing, a program for numerical description of insect wings. J. Insect Sci. 4, 17

Van Dooremalen, C., Stam, E., Gerritsen, L., Cornelissen, B., van der Steen, J., van Langevelde, F., Blacquière, T. (2013) Interactive effect of reduced pollen availability and Varroa destructor infestation limits growth and protein content of young honey bees. J. Insect Physiol. 59 (4), 487-493

Van Valen, L. (1962) A study of fluctuating asymmetry. Evolution. 16(2), 125-142

Wang, D., Moeller, F. (1970) The division of labor and queen attendance behavior of Nosema-infected worker honeybees. J. Econ. Entomol. 63(5), 1539-1541

Willard, L.E., Hayes, A.M., Wallrichs, M.A., Rueppell, O. (2011) Food manipulation in honeybees induces physiological responses at the individual and colony level. Apidologie. 42 (4), 508-518

Windig, J., Nylin, S. (1999) Adaptive asymmetry in wing size in the speckled wood butterfly, Pararge aegeria? Proc. R. Soc. B. 266, 1413-1418 